\title{
An analysis of medical malpractice lawsuits and its relationship to the growth of private hospitals
}

Yu Sun ( $\nabla$ sunyu@nsd.pku.edu.cn )

China Center for Health Economic Research https://orcid.org/0000-0002-6464-5698

Gordon G. Liu

National School of Development, Peking University

Mengxiao Wang

National School of Development, Peking University

Sijia Liu

China Center for Health Economic Research

Research

Keywords: Medical malpractice lawsuits, Private hospitals, Healthcare quality

Posted Date: August 28th, 2020

DOI: https://doi.org/10.21203/rs.3.rs-63474/v1

License: (c) (1) This work is licensed under a Creative Commons Attribution 4.0 International License. Read Full License 


\section{Abstract}

Background Doctor-patient relationship has become an intense concern in public health in recent years. Medical malpractice lawsuits have presented an increasing trend over past decade. This study aims to describe distributions of medical malpractice lawsuits across different provinces and to investigate its relationship to the growth of private hospitals.

Methods Data was drawn from China Judgments Online, the China Health Statistic Yearbooks and China Statistical Yearbooks between January 1, 2010 to December 31, 2016. Private hospitals expansion was measured by the number and proportion of private hospitals, the ratio of outpatient visits from private to public hospitals and the ratio of discharges from private to public hospitals. Fixed-effects negative binomial regressions were utilized to estimate the association between the growth of private hospitals and the number of medical malpractice lawsuits.

Results In total, we identified a total of 18220 lawsuits relevant to medical malpractices across China between 2010 and 2016. The regression results revealed that more private hospitals, larger proportion of private hospitals and higher ratio of discharges from private to public hospitals were significantly associated with fewer medical malpractice lawsuits. An increase of 100 private hospitals in health care market was associated with a decrease in the number of medical malpractice lawsuits by $21 \%$. The ratio of outpatient visits from private to public hospitals was not significantly associated with the number of malpractice lawsuits.

Conclusions There was great disparities of incidences of medical malpractice lawsuits across different provinces. Greater expansion of private hospitals was associated with fewer medical malpractice lawsuits at province level. This negative association indicated that more private hospitals in health care market might provide more incentives for hospitals to contain the incidences of medical malpractice cases.

\section{Introduction}

The number of medical malpractice lawsuits has been increasing rapidly in recent years, reflecting a worsening doctor-patient relationship. Doctor-patient relationship has become an intense concern in public health in recent years in China. Medical malpractice is a critical issue due to incurring economic costs for compensation and loss of trust in the quality of healthcare service in the defendant hospitals. Hospitals may suffer negative impacts on hospital reputation or development [1] and patients may be susceptible to adverse physical or mental outcomes [2]. Moreover, doctors could be accountable for civil and criminal liabilities and under great pressures. A broad body of literature has examined different factors contributing to the growth of medical malpractices from legal perspectives, such as characteristics of liability/compensation systems, and ongoing reforms [3, 4]. However, little research has investigated incidences of medical malpractice incorporating the variations in traits of health care market. 
The role of private hospitals has been increasingly vital in China's health care market as the government intends to use competition from private sector to improve productivity in health care market[5]. The share of private hospitals in health care market is still small, but growing rapidly. The rapid expansion of private hospitals raises concerns about its impacts on health care quality. Empirical work has found that hospital competition may improve the quality of hospital care [6], such as a decrease in mortality from acute myocardial infarction [7] and a lower mortality rates for hemorrhagic stroke [8, 9]. Nevertheless, Encinosa and Bernard have pointed out that decreases in profit margins due to hospital competition are highly associated with adverse health outcomes [10]. Only a few studies examining private hospital care are undertaken in China. In addition, whether the growth of private hospitals is associated with medical malpractices is less investigated. Better knowledge of this association may provide vital implications for future development of private hospitals and implementations of relevant policies to contain medical malpractices. Hence, the objective of this study is to utilize the number of medical malpractices lawsuits as an indicator of health care quality and investigates the association between rapid expansion of private hospitals and incidences of medical malpractice in China.

\section{Background}

\section{Medical malpractice as a measurement of health care quality}

Though other types of quality indicators of health care are utilized in the literature related to evaluation of health care quality, a national collection of those indicators is hard to reach by open access in China. Medical malpractice lawsuits may potentially be a signal of bad quality to patients as information of malpractice lawsuits is easy to access compared to other indicators of healthcare quality. Losing a malpractice lawsuit could bring adverse impacts on hospitals reputation and lead to reducing demand for healthcare services from this hospital in the future. Consequently, hospitals that are frequently involved in medical malpractice lawsuits may not be an optimal choice for patients. Medical malpractice occurrences have been utilized as a measurement of hospital performance $[11,12]$ and suggested to be an indicator of general quality of health care [13]. Hauck et.al. utilize patient complexity adjusted adervse event rates as a measurement of hospital performance and compare rates across different hosptials to evaluate hospital performance [11]. Järvelin and Häkkinen perform anayses at hospital-leve and patientlevel and find that injury claims are siginificantly associated with some aspects of hospital quality, such as revisions and deep infections [13]. Literature also show that records of medical malpractice could be a potential indicator of health care quality in China [12].

Previous studies focusing on health care in China rarely utilize medical malpractice lawsuits as a measurement of health care quality. One possible reason may be because the information of medical malpractices is not available to public until recent years. Medical malpractices were not handled by formal liability rules until 1987 in China. The legislative regulations on medical malpractice has changed since the initiation of the Rules on the Handling of Medical Accidents on June 29, 1987. A further 
progress was achieved as the application of the Regulations on the Handling of Medical Accidents in 2002. The most recent advance was the enaction of "Liability for Medical Malpractice" covered in the Tort Law of the People's Republic of China, which was consolided by the Supreme People's Court in China [14]. After the implementation of "Interim Measures for the Publication of Judgment Documents of the Supreme People's Court Online" in July, 2013, almost all the court judgements are provided online for free. China Judgments Online has provided over 42.6 million public judgment documents by February 2018. When a lawsuit related to malpractice is filed, the inoformation of plaintiff and defendant, the adverse outcomes and case outcomes could be obtained through China Judgements Online. As a result, the occurrences of malpractice lawsuits could constitute a comprehensive and appropriate indicator to measure overall health care quality in China and is utilized in our analyses.

\section{Private hospitals and health care quality}

The private health sector provides alternative health care as public hospitals dominate the hospital industry in China. While, private hospitals provide a wide range of health care services in China, such as outpatient and inpatient services, and screening and diagnostic services. The growth of private hospital has become the subject of debate in recent years as they play an important role in health care market after health care reform in 2009. Figure 1 shows that the number of private hospitals has presented an increasing trend, rising from 5412 in 2010 to 18721 in 2017. In addition, the proportion of inpatients served by private hospitals to those by public hospitals has increased from $4 \%$ in 2009 to $8 \%$ in 2016 [15].

Past literature addressing differences of quality and outcome of health care provided by public hospitals and private hospitals has generated mixed results. In general, public hospitals have lower mortality rates [16-18] and deliver better quality of health care than private hospitals $[19,20]$. While, a few studies have found private hospitals may provide health care services with better quality. For instance, Wüber and Wuckel (2019) [21] find lower 30-day-mortality rates in private hospitals in Germany. As the variations in hospital quality measurements are great, the impacts of private ownership vary across different countries. The effects of private hospitals on health care quality are not definitive in China as few studies focusing on the relationship between private hospitals and health care quality have been carried out in China.

\section{Methods}

\section{Data}

We drew data from three sources: medical malpractice lawsuits from China Judgments Online, the China Health Statistic Yearbooks and China Statistical Yearbooks. We identified medical malpractice lawsuits from China Judgments Online and extracted related case information such as the filing date and location. Malpractice lawsuits were searched between January 1, 2010 to December 31, 2016. The records referred to the universe injuries claimed as a result of actual/perceived medical or surgical mistakes by health care professionals. We then excluded records with missing information of location and filing date, as well as records of duplicated cases. Other types of data at provincial level were from 
the China Health Statistic Yearbook, such as per capita household income, the urban employee/resident health insurance coverage, and number of hospitals, etc. Population in each province over the period from 2010 to 2016 was from China Statistical Yearbook.

The count of medical malpractice lawsuits was a good proxy for measuring health care quality as discussed in previous section [22]. Accordingly, the primary variable of interest was the occurrences of medical malpractice lawsuits at the province level during a year.

Private hospitals expansion were measured following the strategies proposed by Liu et al. [23]. First, we used the number of private hospitals in the health care market in each province and the proportion of its quantity to the number of total hospitals. Then, we measured the relative size of private hospitals and for the health care market structure: the ratio of outpatient visits in private hospitals to public hospitals and the ratio of discharges from private hospitals over those in public hospitals.

Other independent variables mainly included variables reflecting features of healthcare, hospital characteristics and social economic factors as well. Number of doctors per 1000 people and proportion of first-class public hospitals revealed the local supply side of health care services. The coverage rates of the urban employee/resident basic health insurance indicated the fraction of local population who were covered by the insurance benefits. Per capita GDP was an indicator of income level and a vital driver of health service use. It was adjusted to 2010 Chinese Yuan by consumer price index. As high proportion of

people aged 65 and over reflected increasing healthcare needs to meet [24], the proportion of people aged 65 and over was utilized to indicate the diverse needs of health care at different provinces. The ratio of females was used because the likelihood to file a medical malpractice claim is different between males and females $[25,26]$. Proportion of urban residents was included because a greater urbanization might be associated with more medical malpractice claims [25]. Regional factors were accounted for by including dummy variables for West, East, Northeast and Central.

\section{Statistical analysis}

The hypothesis that we intend to test is whether the expansion of private hospitals have impacts on the occurrences of medical malpractice lawsuits. Since the dependent variable is the number of medical malpractice lawsuits occurred in each province by calendar year, we choose a set of models to explore the association between private hospitals expansion and healthcare quality. Problem of endogeneity may arise in cross-sectional analyses if there are unobserved factors that are correlated with the measurement of private hospital expansions and the occurrences of medical malpractice lawsuits. For example, cultural factors may affect patients' choices between private and public hospitals [27], as well as choice of health insurance. Thus, cultural factors may have impacts on health care market. On the other hand, cultural factors may contribute to the decision of pursuing medical malpractice lawsuits [28]. Hence, we utilize the longitudinal nature of the data to control for unobserved province-level fixed effects via fixedeffects count panel models. 
Estimation of count panel data is well discussed by Boucher \& Guillen (2009) [29], Cameron and Travidi (1998) [30], Hausman et al (1984) [31] and Winkelmann (2008) [32]. Fixed effects Poisson model is the basic model for count panel data. Based upon previous studies, the fixed effects Poisson model is specified as following:

$$
\mu_{\mathrm{it}}=\exp \left(\delta_{i}+\beta X_{\text {it }}\right)
$$

Where $\delta_{i \text { is the fixed effects parameter, }} X_{\text {it is a vector of explanatory variables, }}$ including indicators of private hospitals expansion and characteristics of healthcare demand, hospitals and social-economic factors at province level.

The Poisson distribution has a strong restriction that mean equals variance. This assumption is often violated due to unobserved heterogeneity. The negative binomial distribution is appropriate to account for the over-dispersion. Following Hausman et al. [31], negative binomial model with fixed effects could be specified as following:

$$
\mathrm{f}\left(\mathrm{y}_{i t} \mid \lambda_{i t}, \theta_{i}\right)=\frac{\Gamma\left(\lambda_{i t}+\mathrm{y}_{i t}\right)}{\Gamma\left(\lambda_{i t}\right) \Gamma\left(\mathrm{y}_{i t}+1\right)}\left(\frac{1}{1+\theta_{i}}\right)^{\lambda_{i t}}\left(\frac{\theta_{i}}{1+\theta_{i}}\right)^{\mathrm{y}_{t}}
$$

With $\mathrm{E}\left(\mathrm{y}_{\ddot{t i}}\right)=\theta_{i} \lambda_{i t}$ and $\operatorname{var}\left(\mathrm{y}_{\text {it }}\right)=\left(1+\theta_{i}\right) \theta_{i} \lambda_{\text {it }}$

Where $\Gamma_{\text {represents a gamma function, }} \theta_{i}$ is assumed to be constant overtime.

Estimations of parameters are undertaken by maximum likelihood methods and results are estimated using the STATA 15 software [33].

\section{Results}

Table 1 presented the total number of medical malpractice lawsuits, the average number of malpractice lawsuits per million outpatient visits and per million population in each province. The first column showed that there were great disparities of the incidences of medical malpractice lawsuits across different provinces. For example, populous provinces were likely to observe more medical malpractice lawsuits, such as Jiangsu, Shandong and Henan. While, total malpractice lawsuits per million visits were much higher in Jilin, Anhui and Chongqing than other provinces.

Several patterns could be identified from comparisons of total number of malpractice lawsuits with the average number of malpractice lawsuits per million population. Some provinces were characterized with relatively low total malpractice lawsuits and higher population-averaged number of malpractice lawsuits, 
such as Beijing and Shanghai. This pattern showed that medical malpractice lawsuits arose more often in large cities, indicating a potential migration of cases from other regions. Some provinces were perceived with low total and population-averaged number of malpractice lawsuits, such as Gansu and Hainan. While others were observed with high total and population-averaged number of malpractice lawsuits, such as Jilin and Jiangsu.

Table 2 presented the summary statistics for provincial variables. The average occurrences of malpractice lawsuits were about three times greater in 2013 compared to that in 2012. This dramatic increase might be due to the initiation of "Liability for Medical Malpractice" in 2013. The proportion of private hospitals showed an increasing trend from 33\% in 2010 to 54\% in 2016. Accordingly, the ratio of outpatient visits and discharges from private hospitals to public hospitals had been rising over the same period. On average, the total number of hospitals has been increased about $25 \%$ in 2016 . The number of doctors per 1000 people in each province had increased slightly from 1.67 to 2 . The proportion of firstclass public hospitals remained stable around $8 \%$. Both the coverage of UEBMI and URBMI presented an upward trend, ranging from $16 \%$ to $29 \%$. The health care expenditures had been growing rapidly from 783.61 hundred million of Yuan in 2010 to 1,409.77 hundred million of Yuan in 2016. Proportion of people aged 65 and above grew to reach $10.56 \%$ in 2016 . More than a half ( $52 \%$ in 2010 vs. $59 \%$ in 2016 ) of the population were urban residents. With respect to log of per capita household income, small changes were observed between 2010 and 2016 after adjusting for CPI in each year.

Regression results showed that the over-dispersion parameters were significantly different from 0 , indicating that the negative binomial models were preferred over Poisson models. The results of fixedeffects negative binomial models were reported in Table 3 to account for potential endogeneity of the time-invariant unobserved provincial factors as discussed in previous sections. Further, Akaike Information Criterion (AIC) indicated that fixed-effects negative binomial models were superior to randomeffects counterpart. Year dummies were added to specify time effects in all provinces. Moreover, an indicator of initiation of "Liability for Medical Malpractice" (e.g. "Indicator of Liability for Medical Malpractice") were included in the regression models to account for the shifts in legal environment. Indicators of regions were also incorporated into the models.

In Table 3, we see that greater expansion of private hospitals (measured by "Total number of private hospitals", "Proportion of private hospitals" and "Ratio of discharges from private to public hospitals") were associated with fewer medical malpractice lawsuits, and this association was statistically significant at the $10 \%$ level of significance at least. Specifically, the first column of Table 3 presented the results using total number of private hospitals as an indicator of private hospital expansion. More private hospitals in health care market were associated with less medical malpractice lawsuits. Column (1) presented that an increase of 100 private hospitals in health care market was expected to have a decrease of $21 \%(=1-\exp (-0.23))$ in the number of medical malpractice lawsuits holding all other variables constant. Column (2) investigated the proportion of private hospitals and showed a significantly negative correlation with the occurrences of medical malpractice lawsuits in each province. Column (3) presented the results of regressions using ratio of outpatient visits from private hospitals to public hospitals to 
measure the expansion of private hospitals. The coefficients indicated that there was a positive association between expansion of private hospitals and the ratio of outpatient visits from private to public hospitals, but the correlation was not statistically significant. In column (4), we could see that higher ratio of discharges from private hospitals to public hospitals was negatively and significantly correlated with incidences of medical malpractice lawsuits in each province.

The results in Table 3 also reported other significant variables. The proportion of people aged 65 and above was not significantly associated with the number of malpractice lawsuits. This finding was supported by a previous study, which found that demographic variables were not associated with frequency of medical malpractice claims[25]. While, proportion of females was positively related to the occurrences of medical malpractice lawsuits in three out of four models, and this relationship was significant at $10 \%$ level. Higher proportion of urban residents was significantly associated with greater medical malpractice lawsuits. Previous studies suggested that increasing urbanization might contribute to the filed medical malpractice claims because patients in urban hospitals might have greater propensity to litigate a malpractice injuries[25]. More doctors per 1000 people and higher per capita household income were associate with higher amount of medical malpractice lawsuits. Both coverage rate of UEBMI and URBMI were negatively associated with the malpractice lawsuits, but only statistically significant for coefficients for UEBMI. Ramseyer (2009) [34]found that universal health insurance system in Japan prompted the government to cover the rudimentary health services and suppressed the price for sophisticated procedures. Hence, it was possible that the medical malpractices showed a decreasing trend because patients were less likely to sue over primary health care. The positive sign of the Indicator of Liability for Medical Malpractice suggested that more lawsuits were expected to occur after the initiation of Liability for Medical Malpractice in 2013. The coefficients for total health expenditures were negative and significant, implying that health care expenditures were negatively associated with medical malpractice lawsuits. Volume-outcome relationship could be a source of explanations for this finding. According to a systematic review, better outcomes were associated with higher hospital volume[35]. As health care expenditure was usually considered as measurement of health care utilization, it was possible that greater health care services might improve the hospital quality.

To check the robustness of our results, we first utilize the lagged indicators of private hospitals expansion in regression analyses. Table 4 showed the estimation results using one-year-lagged measurement of private hospitals expansion. The directions of the association between the growth of private hospitals and the number of medical malpractice lawsuits were in accordance with our expectation, indicating the growth of private hospitals was negatively associated with the incidences of medical malpractice lawsuits. However, the association was only significant at $10 \%$ level in models utilizing proportion of private hospitals and ratio of discharges from private to public hospitals. Further, we restricted the sample between 2013 and 2016 to examine the association because almost all judgement documents became publicly available in 2013.

Table 5 presented the results of regressions using restricted sample. Higher ratio of the discharges was significantly associated with fewer medical malpractice lawsuits. There was no significant association 
between other indicators of private hospitals expansion and the incidences of medical malpractice lawsuits. In general, our results were robust in different specifications.

\section{Discussion}

The past decade has witnessed a dramatic increase in both private hospitals and medical malpractice lawsuits in China. However, very few studies have investigated whether the expansion of private hospitals is associated with the increasing trend of medical malpractice lawsuits. Medical malpractice injuries have raised much concerns around health care quality and the upward trend of medical malpractice lawsuits reflected a worsening relationship between patients and doctors. Previous literature has investigated various aspects of medical malpractices, such as trend and determinants. While, few studies have explored the occurrences of medical malpractices from the perspective of changes in health care market.

The results in this study reveal that greater private hospitals expansion in health care market may contribute to a decrease in the number of medical malpractice lawsuits, indicating that private hospitals expansion may bring benefits to health care services in China. This finding is consistent with several studies focusing on evaluation of impacts of private hospitals in China. For instance, Liu et al. (2009) [23]uses data at the province level to explore the relationship between private hospital penetration and health care spending and find that for-private hospitals is negatively associated with average medical expenditures. Pan et al. find that hospital competition contributes to improved measurements of health care quality[36]. While, Eggleston et al. find the ownership of hospitals are systematically related to health care, but the evidences are mixed[18]. For example, some studies find that mortality rates [37] and the likelihood of dying [38] are lower in private sectors. Another study also found lower 30-day-mortality rates for pneumonia patients in private hospitals[21]. While, the rates of 30-day all-cause rehospitalizations of older patients are higher in private hospitals than public hospitals[39].

There are several underlying channels through which the expansion of private hospitals may affect the number of medical malpractice lawsuits. First, it is possible that hospitals in a more competitive health care market have greater incentives to improve health care quality. Though public hospitals dominate the health care market in China, greater private hospitals expansion contributes to a competitive hospital market. Second, in regions with more private hospitals, such as in Eastern China (40.4\%) [15]and relatively developed areas $[40,41]$, it would be preferred to use alternative methods to solve medical disputes rather than litigation. Alternative methods for solving medical disputes include negotiation, people's mediation, administrative mediation, litigation, and other legal routes[42]. Litigation is usually more time-consuming and can exert a negative effect on hospital's reputation compared to alternative methods $[43,44]$. Hence, eastern areas are motivated to resolve to alternative ways to overcome difficulties in public governance brought by large migrant population. Third, increasing access promoted by private hospitals can provide more convenience for patients and may help with early detection and early treatment and lead to less disputes. A study shows that the spatial accessibility of private hospitals have already surpassed public hospitals at primary level in Eastern Sichuan[40]. Accordingly, preventing 
the deterioration of patients' conditions due to improved access to medical services may reduce medical injuries and medical disputes. Fourth, more private hospitals may contribute to less medical disputes by lower health expenditures. Past literature shows that there is a negative relationship between growth of private hospitals and medical service prices[23]. Accordingly, the expansion of private hospitals in health care market could be associated with fewer medical malpractice lawsuits.

The fundamental solutions for controlling growth of medical malpractice injuries should provide adequate incentives for doctors to practice with care. Increased competition in health care markets will put stress on hospitals to improve management and quality [4]. Besides building a more competitive hospital market, other aspects should also be paid attention to. For example, information shared in health care market. As pointed out by Danzon, "if patients are well informed, market forces would eliminate practitioners whose quality of care fell short of that preferred by patients" [45]. Hence, strategies aim to build a more competitive health care market should also take into account of information sharing in future policy designs to form a more effective health care market.

There are several limitations with this study. First, only aggregate number of medical malpractice lawsuits were utilized in this study. The coefficients in our regression results may be upward biased because we use the number of filed lawsuits of medical malpractice injuries. But hospitals are not primarily responsible for all the medical malpractices. Future study should further explore the association between expansion of private hospitals and medical malpractice lawsuits at micro level to examine factors associated with hospitals and patients that have higher likelihood of getting involved in malpractice lawsuits, such as the impact of physician's behavior or hospital management on medical malpractices lawsuits. Second, the fixed-effects models dealt with time-invariant unobserved factors that may contribute to endogeneity problems. However, potential endogenous variables that change over time could not be addressed by fixed-effects models. Hence, the causal association between expansion of private hospitals and medical malpractice lawsuits could not be rigorously established in this study.

\section{Conclusions}

The impacts of private hospitals expansion have spurred an important debate in the past decade as a rapid increasing trend of private hospitals is present in health care market. In this study, the growth of private hospitals was measured by different indicators and the health care quality was measured by the number of medical malpractice lawsuits in each province. The results show that greater expansion of private hospitals is associated with less medical malpractice lawsuits at province level. The findings imply that more competitive health care market may contribute to improvement in overall health care quality.

\section{Abbreviations}

AIC

Akaike Information Criterion 
CPI

Consumer price index

GDP

Gross domestic product

UEBMI

Urban Employee Basic Medical Insurance

URBMI

Urban Resident Basic Medical Insurance

\section{Declarations}

Ethics approval and consent to participate

Not applicable

Consent for publication

Not applicable

Availability of data and materials

The datasets used and/or analyzed during the current study are available from the corresponding author on reasonable request.

Competing interests

The authors declare that they have no competing interests.

Funding

This study is supported by Peking University China Center for Health Economic Research (CCHER).

Authors' contributions 
GL contributed to the research concept and design, and offered critical suggestions for revisions. YS was in charge of overall planning and implementation of the research. YS and MX wrote the manuscript. YS and SJ conducted data collection and analyses. YS and MX interpreted the results. All authors read and approved the final manuscript.

Acknowledgements

Not applicable.

\section{References}

1. Xiao H. The influence of medical dispute on medical and health services [in Chinese]. Chinese Journal of Coal Industry Medicine. 2016;19:1381-6.

2. Yan L, Zhang S, Wang Y. Investigation of the influence of medical disputes on patients [in Chinese]. Hospital Administration Journal of Chinese People's Liberation Army. 2004;11:158.

3. Kessler DP. Evaluating the medical malpractice system and options for reform. Journal of Economic Perspectives. 2011;25:93-110.

4. Yang L, Xi C. The rise and decline of the reversal of the burden of proof in china's medical negligence law: A political economy of lawmaking perspective. China Review. 2012;12:33-58.

5. Yip W, Hsiao W. Harnessing the privatisation of China's fragmented health-care delivery. The Lancet. 2014;384:805-18.

6. Vogt WB, Town R, Williams $\mathrm{CH}$. How has hospital consolidation affected the price and quality of hospital care? INQUIRY: The Journal of Health Care Organization, Provision, and Financing; 2006.

7. Cooper Z, et al. Does hospital competition save lives? Evidence from the English NHS patient choice reforms. Econ J. 2011;121:F228-60.

8. Bloom N, et al. The impact of competition on management quality: Evidence from public hospitals. Rev Econ Stud. 2015;82:457-89.

9. Liao $\mathrm{CH}$, et al. Assessing the relationship between healthcare market competition and medical care quality under Taiwan's National Health Insurance programme. Eur J Pub Health. 2018;28:1005-11.

10. Encinosa WE, Bernard DM. Hospital finances and patient safety outcomes. Inquiry. 2005;42:60-72.

11. Hauck K, Zhao X, Jackson T. Adverse event rates as measures of hospital performance. Health Policy. 2012;104:146-54.

12. Wang Z, et al. Records of medical malpractice litigation: a potential indicator of health-care quality in China. Bull World Health Organ. 2017;95:430-6.

13. Järvelin J, Häkkinen U. Can patient injury claims be utilised as a quality indicator? Health Policy. 2012;104:155-62. 
14. Oliphant K, Wright RW. Medical malpractice and compensation in global perspective. Journal of European Tort Law, 2016. 7.

15. Commission NH. China Health Statistical Yearbook. 2019.

16. Schlesinger M, Marmor TR, Smithey R. Nonprofit and for-profit medical care: shifting roles and implications for health policy. J Health Polit Policy Law. 1987;12:427-57.

17. Devereaux PJ, et al. Payments for care at private for-profit and private not-for-profit hospitals: a systematic review and meta-analysis. Cmaj. 2004;170:1817-24.

18. Eggleston $\mathrm{K}$, et al. Hospital ownership and quality of care: What explains the different results in the literature? Health Econ. 2008;17:1345-62.

19. Currie G, Donaldson C, Lu M, What does Canada profit from the for-profit debate on health care? Canadian Public Policy, 2003. 29: p. 227-251.

20. Rosenau PV, Linder SH. A comparison of the performance of for-profit and nonprofit U.S. psychiatric inpatient care providers since 1980. Psychiatric Services. 2003;54:183-7.

21. Wübker A, Wuckel C. The Impact of Private for-Profit Hospital Ownership on Costs and Quality of Care - Evidence from Germany. CESifo Economic Studies. 2019;65:373-401.

22. Buzzacchi L, Scellato G, Ughetto E. Frequency of medical malpractice claims: The effects of volumes and specialties. Soc Sci Med. 2016;170:152-60.

23. Liu GG, et al. The role of for-profit hospitals in medical expenditures: Evidence from aggregate data in China. China Econ Rev. 2009;20:625-33.

24. Zhang T, Chen Y, Meeting the needs of elderly people in China. 2006, British Medical Journal Publishing Group.

25. Duff DG, Trebilcock MJ, Dewees DN, The medical malpractice explosion: an empirical assessment of trends, determinants, and impacts. Social Science Electronic Publishing., 1990. 17: p. 539.

26. Bertakis KD, et al. Gender Differences in the Utilization of Health Care Services. J Fam Pract. 2000;49:147-52.

27. Lepore $L$, et al. Cultural orientations and information systems success in public and private hostitals: Preliminary evidences from Italy. BMC Health Services Research. 2018;18:554.

28. Colombo F, Tapay N, Private Health Insurance in OECD Countries. Health San Francisco, 2004: p. 0.

29. Boucher JP, Guillén M. A survey on models for panel count data with applications to insurance. Revista de la Real Academia de Ciencias Exactas, Fisicas y Naturales - Serie A: Matematicas, 2009. 103: p. 277-294.

30. Cameron C, Trivedi P. Regression Analysis of Count Data. 1998.

31. Hausman J, Hall BH, Griliches Z. Econometric Models for Count Data with an Application to the Patents-R \& D Relationship, in Econometrica. Mass.: national bureau of economic research Cambridge; 1984. p. 909.

32. Winkelmann R, Zimmermann KF. Recent Developments in Count Data Modelling: Theory and Application. J Economic Surveys. 1995;9:1-24. 
33. StataCorp. Stata Statistical Software: Release 15. 2017.

34. Ramseyer JM. The Effect of Universal Health Insurance on Malpractice Claims: The Japanese Experience. Journal of Legal Analysis. 2010;2:621-86.

35. Halm EA, Lee C, Chassin MR. Is volume related to outcome in health care? A systematic review and methodologic critique of the literature. Ann Intern Med. 2002;137:511-20.

36. Pan J, et al. Does hospital competition improve health care delivery in China? China Econ Rev. 2015;33:179-99.

37. Tiemann O, Schreyögg J. Effects of Ownership on Hospital Efficiency in Germany. Business Research. 2009;2:115-45.

38. Berta P, Seghieri C, Vittadini G. Comparing health outcomes among hospitals: The experience of the Lombardy Region. Health Care Management Science. 2013;16:245-57.

39. Gusmano M, et al. Comparison of rehospitalization rates in France and the United States. Journal of Health Services Research Policy. 2015;20:18-25.

40. Pan J, et al. Assessing spatial access to public and private hospitals in Sichuan, China: The influence of the private sector on the healthcare geography in China. Soc Sci Med. 2016;170:35-45.

41. Jin K, et al. Comparing public and private emergency departments in China: Early evidence from a national healthcare quality survey. International Journal of Health Planning Management. 2020;35:581-91.

42. Council S. Medical Disputes Prevention and Treatment Regulations. 2018.

43. Zhou C, et al. Study on factors inducing workplace violence in Chinese hospitals based on the broken window theory: a cross-sectional study. BMJ Open. 2017;7:e016290.

44. Wang $\mathrm{M}$, et al. The role of mediation in solving medical disputes in China. BMC Health Services Research. 2020;20:225.

45. Danzon PM. An Economic Analysis of the Medical Malpractice System. Behavioral Sciences The Law. 1983;1:39-54.

\section{Tables}

Table 1. Description of the number of medical malpractice lawsuits by province in China over 2010-2016 


\begin{tabular}{|llll|}
\hline Province & Total & $\begin{array}{l}\text { Per million } \\
\text { visits }\end{array}$ & Per million population \\
& & \\
\hline Anhui & 1165 & 1.65 & 0.24 \\
\hline Beijing & 828 & 0.77 & 0.5 \\
\hline Chongqing & 538 & 1.42 & 0.27 \\
\hline Fujian & 363 & 0.61 & 0.15 \\
\hline Gansu & 167 & 0.64 & 0.1 \\
\hline Guangdong & 841 & 0.32 & 0.1 \\
\hline Guangxi & 484 & 0.82 & 0.14 \\
\hline Guizhou & 256 & 0.86 & 0.12 \\
\hline Hainan & 56 & 0.5 & 0.1 \\
\hline Hebei & 866 & 1.04 & 0.15 \\
\hline Heilongjiang & 493 & 1.01 & 0.16 \\
\hline Henan & 1596 & 1.34 & 0.22 \\
\hline Hubei & 945 & 1.09 & 0.21 \\
\hline Hunan & 730 & 1.11 & 0.14 \\
\hline Inner Mongolia & 214 & 0.88 & 0.15 \\
\hline Jiangsu & 1728 & 1 & 0.29 \\
\hline Jiangxi & 451 & 0.98 & 0.13 \\
\hline Jilin & 1256 & 3.11 & 0.55 \\
\hline Liaoning & 729 & 1.06 & 0.22 \\
\hline Ningxia & 124 & 1.1 & 0.28 \\
\hline Qinghai & 40 & 0.82 & 0.15 \\
\hline Shaanxi & 392 & 0.72 & 0.13 \\
\hline Shandong & 1646 & 1.23 & 0.22 \\
\hline Shanghai & 995 & 1.3 & 0.76 \\
\hline Shanxi & 382 & 1.14 & 0.15 \\
\hline Sichuan & 0.7 & 0.13 \\
\hline
\end{tabular}




\begin{tabular}{|llll|}
\hline Xinjiang & 302 & 1.11 & 0.24 \\
\hline Yunnan & 375 & 0.62 & 0.11 \\
\hline Zhejiang & 1035 & 0.58 & 0.23 \\
\hline
\end{tabular}

Source: Data of population is from China Statistical Yearbook and total number of outpatient visits is from Chinese Health Statistics Yearbook.

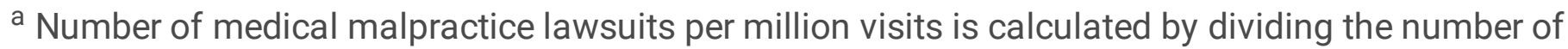
outpatient visits in each year and then averaged across 2010-2016.

${ }^{\mathrm{b}}$ Number of medical malpractice lawsuits per million population is calculated by dividing the population in each year and then averaged across 2010-2016.

Table 2. Summary statistics for provincial variables 


\begin{tabular}{|c|c|c|c|c|c|c|c|}
\hline Variables & 2010 & 2011 & 2012 & 2013 & 2014 & 2015 & 2016 \\
\hline \multicolumn{8}{|l|}{ Outcome } \\
\hline $\begin{array}{l}\text { Number of } \\
\text { malpractice lawsuits }\end{array}$ & 163 & 318 & 963 & 2,900 & 4,384 & 5,273 & 4,219 \\
\hline \multicolumn{8}{|l|}{$\begin{array}{l}\text { Indicators of private } \\
\text { hospitals expansion }\end{array}$} \\
\hline $\begin{array}{l}\text { Proportion of private } \\
\text { hospitals (\%) }\end{array}$ & 0.33 & 0.37 & 0.41 & 0.43 & 0.47 & 0.51 & 0.54 \\
\hline $\begin{array}{l}\text { Ratio of outpatient } \\
\text { visits from private to } \\
\text { public hospitals (\%) }\end{array}$ & 0.09 & 0.1 & 0.11 & 0.14 & 0.12 & 0.14 & 0.14 \\
\hline $\begin{array}{l}\text { Ratio of discharges } \\
\text { from private to public } \\
\text { hospitals (\%) }\end{array}$ & 0.09 & 0.1 & 0.12 & 0.13 & 0.14 & 0.16 & 0.17 \\
\hline \multicolumn{8}{|l|}{$\begin{array}{l}\text { Healthcare and } \\
\text { hospital } \\
\text { characteristics }\end{array}$} \\
\hline $\begin{array}{l}\text { Total number of } \\
\text { hospitals }\end{array}$ & 776.24 & 823.91 & 790.48 & 820.1 & 858.27 & 914.93 & 966.5 \\
\hline $\begin{array}{l}\text { Number of doctors } \\
\text { per } 1000 \text { people }\end{array}$ & 1.67 & 1.7 & 1.67 & 1.87 & 1.81 & 1.9 & 2 \\
\hline $\begin{array}{l}\text { Proportion of first- } \\
\text { class public hospitals }\end{array}$ & 0.07 & 0.07 & 0.07 & 0.08 & 0.08 & 0.08 & 0.08 \\
\hline $\begin{array}{l}\text { Total health } \\
\text { expenditure, hundred } \\
\text { millions of Yuan }\end{array}$ & 783.61 & 911.69 & 955.11 & $1,068.55$ & $1,196.11$ & $1,367.06$ & $1,409.77$ \\
\hline $\begin{array}{l}\text { Coverage rate of } \\
\text { UEBMI (\%) }\end{array}$ & 0.16 & 0.18 & 0.22 & 0.23 & 0.24 & 0.24 & 0.29 \\
\hline $\begin{array}{l}\text { Coverage rate of } \\
\text { URBMI }(\%)\end{array}$ & 0.19 & 0.21 & 0.21 & 0.22 & 0.22 & 0.22 & 0.23 \\
\hline \multicolumn{8}{|l|}{$\begin{array}{l}\text { Social-economic } \\
\text { factors }\end{array}$} \\
\hline $\begin{array}{l}\text { Log of per capita } \\
\text { household income }\end{array}$ & 9.79 & 9.96 & 10.04 & 10.12 & 9.85 & 9.93 & 10.02 \\
\hline $\begin{array}{l}\text { Proportion of people } \\
\text { aged } 65 \text { and above } \\
\text { (\%) }\end{array}$ & 8.82 & 9.24 & 10.32 & 9.4 & 9.7 & 10.18 & 10.56 \\
\hline $\begin{array}{l}\text { Proportion of urban } \\
\text { residents (\%) }\end{array}$ & 51.54 & 54.55 & 54.7 & 55.48 & 56.55 & 57.61 & 58.79 \\
\hline Number of & 21 & 22 & 29 & 30 & 30 & 30 & 30 \\
\hline
\end{tabular}


Note: UEBMI represents Urban Employee Basic Medical Insurance; URBMI represents Urban Resident Basic Medical Insurance. Proportion of private hospitals is the ratio of number of private hospitals to the number of total hospitals. Proportion of visits from private hospitals is ratio of the number of visits from private hospital to the number of visits from private and nonprofit hospitals. Proportion of discharges from private hospitals is the ratio of discharges from private hospital to the number of discharges from private and nonprofit hospitals. Coverage rate of UEBMI is dividing number of individuals who have UEBMI by total population in that province. Coverage rate of URBMI is dividing number of individuals who have URBMI by total population in that province.

Table 3. Estimation results of fixed effects negative binomial models for various indicators of expansion of private hospitals. 
Coefficient estimates

(1)

$\begin{array}{ll}\text { Total number of private hospitals } & -0.23 * \\ & (0.12)\end{array}$

$\begin{array}{ll}\text { Total number of private hospitals } & -0.23^{*} \\ & (0.12)\end{array}$

Coefficient estimates

(2)
Coefficient estimates

(3)
Coefficient estimates
Proportion of private hospitals
$-2.75^{\star \star}$
(1.21)

Ratio of outpatient visits from

private to public hospitals

0.66

$(0.53)$

Ratio of discharges from private to

public hospitals

Proportion of people aged 65 and

0.00

0.00

0.00

0.00 above
$(0.00)$

(0.00)

$(0.00)$

$(0.00)$

Proportion of urban residents

$0.07^{\star \star \star}$

$0.06^{* *}$

0.06 *ᄎ

$0.06^{* *}$

(0.02)

(0.02)

(0.02)

(0.02)

Proportion of females

6.87*

(3.57)

$6.89 *$

6.16*

$6.88^{*}$

Prop of doctors per 1000 people

Number of doctors per 1000 people

$0.28^{*}$

(3.55)

(3.45)

(0.15)

0.31 **

0.22

0.20

(0.15)

(0.15)

(0.15)

Log of per capita household income

$2.33^{\star \star \star}$

(0.68)

$2.55^{\star \star \star}$

$2.02^{\star \star *}$

$2.17 * \star \star$

Coverage rate of UEBMI

$-5.92^{\star \star}$

(0.68)

(0.64)

(0.64)

(2.48)

$-5.53^{\star *}$

$-5.97 * \star$

$-5.83^{* *}$

Coverage rate of URBMI

$-0.40$

(2.49)

(2.32)

(2.33)

Proportion of first-class public
hospitals

(0.49)

$-0.49$

$-0.56$

$-0.53$

(0.48)

(0.51)

(0.49)

$-3.08$

$-3.14$

$-0.75$

$-2.05$

(4.36)

(4.36)

(4.27)

(4.22)

West (Reference) 


\begin{tabular}{|c|c|c|c|c|}
\hline \multirow[t]{2}{*}{ East } & -0.34 & -0.12 & -0.27 & -0.20 \\
\hline & $(0.67)$ & $(0.66)$ & $(0.67)$ & $(0.68)$ \\
\hline \multirow[t]{2}{*}{ Central } & 0.82 & $0.90 *$ & $0.90 *$ & $0.87 *$ \\
\hline & $(0.50)$ & $(0.49)$ & $(0.49)$ & $(0.50)$ \\
\hline \multirow[t]{2}{*}{ Northeast } & 0.89 & 1.21 & 1.09 & 1.29 \\
\hline & $(0.86)$ & $(0.85)$ & $(0.83)$ & $(0.94)$ \\
\hline \multirow{2}{*}{$\begin{array}{l}\text { Indicator of Liability for Medical } \\
\text { Malpractice }=1\end{array}$} & $3.69 \star \star \star$ & $4.06^{\star \star \star}$ & $3.38^{\star \star \star}$ & $3.66^{\star \star \star}$ \\
\hline & $(0.46)$ & $(0.50)$ & $(0.43)$ & $(0.46)$ \\
\hline \multirow{2}{*}{$\begin{array}{l}\text { Total health expenditure, hundred } \\
\text { millions of Yuan }\end{array}$} & $-0.00 * \star \star$ & $-0.00 * \star \star$ & $-0.00 * \star \star$ & $-0.00 * \star \star$ \\
\hline & $(0.00)$ & $(0.00)$ & $(0.00)$ & $(0.00)$ \\
\hline \multirow[t]{2}{*}{ Total number of hospitals } & $0.00 \star \star$ & $0.00 \star \star$ & 0.00 & $0.00 *$ \\
\hline & $(0.00)$ & $(0.00)$ & $(0.00)$ & $(0.00)$ \\
\hline Year dummies & $\sqrt{ }$ & $\sqrt{ }$ & $\sqrt{ }$ & $\sqrt{ }$ \\
\hline \multirow[t]{2}{*}{ Constant } & 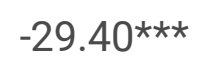 & 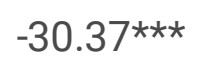 & $-25.37 \star \star \star$ & $-26.65^{\star \star \star}$ \\
\hline & $(7.30)$ & (7.09) & $(6.80)$ & $(6.73)$ \\
\hline AIC & 1096.53 & 1094.82 & 1098.38 & 1096.60 \\
\hline $\mathrm{BIC}$ & 1161.88 & 1160.17 & 1163.73 & 1161.95 \\
\hline Observations & 166 & 166 & 166 & 166 \\
\hline
\end{tabular}

Notes for variables are the same as in Table 1.

Standard errors in parentheses

${ }^{\star} p<0.1,{ }^{* \star} p<0.05,{ }^{* \star \star} p<0.0$ expansion of private hospitals. 


\begin{tabular}{|c|c|c|c|c|}
\hline & $\begin{array}{l}\text { Coefficient } \\
\text { estimates } \\
\text { (1) }\end{array}$ & $\begin{array}{l}\text { Coefficient } \\
\text { estimates } \\
\text { (2) }\end{array}$ & $\begin{array}{l}\text { Coefficient } \\
\text { estimates } \\
\text { (3) }\end{array}$ & $\begin{array}{l}\text { Coefficient } \\
\text { estimates } \\
\text { (4) }\end{array}$ \\
\hline \multirow[t]{2}{*}{$\begin{array}{l}\text { Total number of private hospitals in } \\
\text { past year }\end{array}$} & -0.01 & & & \\
\hline & $(0.14)$ & & & \\
\hline \multirow{2}{*}{$\begin{array}{l}\text { Proportion of private hospitals in } \\
\text { past year }\end{array}$} & & $-2.47 *$ & & \\
\hline & & (1.31) & & \\
\hline \multirow{2}{*}{$\begin{array}{l}\text { Ratio of outpatient visits from private } \\
\text { hospitals in past year }\end{array}$} & & & -0.46 & \\
\hline & & & (1.07) & \\
\hline \multirow{2}{*}{$\begin{array}{l}\text { Ratio of discharges from private } \\
\text { hospitals in past year }\end{array}$} & & & & $-6.88^{*}$ \\
\hline & & & & (3.26) \\
\hline Observations & 136 & 136 & 136 & 136 \\
\hline
\end{tabular}

Control variables are the same as in Table 1.

Standard errors in parentheses

$\star p<0.1, * \star p<0.05, * \star \star p<0.01$

Table 5. Estimation results of fixed effects negative binomial models for various indicators of expansion of private hospitals (2013-2016). 


\begin{tabular}{|lllll|}
\hline & $\begin{array}{l}\text { Coefficient } \\
\text { estimates } \\
(1)\end{array}$ & $\begin{array}{l}\text { Coefficient } \\
\text { estimates } \\
(2)\end{array}$ & $\begin{array}{l}\text { Coefficient } \\
\text { estimates } \\
(3)\end{array}$ & $\begin{array}{l}\text { Coefficient } \\
\text { estimates }\end{array}$ \\
\hline $\begin{array}{l}\text { Total number of private } \\
\text { hospitals }\end{array}$ & -0.11 & & $(4)$ \\
\hline Proportion of private hospitals & $(0.19)$ & & & \\
\hline $\begin{array}{l}\text { Ratio of outpatient visits from } \\
\text { private hospitals }\end{array}$ & -2.58 & 0.91 & \\
\hline $\begin{array}{l}\text { Ratio of discharges from private } \\
\text { hospitals }\end{array}$ & $(1.60)$ & & $(0.58)$ & \\
\hline & & & & -3.30 ** \\
\hline \begin{tabular}{l} 
Observations \\
\hline
\end{tabular} & 97 & 97 & 97 & 97 \\
\hline
\end{tabular}

Control variables are the same as in Table 1.

Standard errors in parentheses

$\star p<0.1, * \star p<0.05, \star \star \star p<0.01$

\section{Figures}




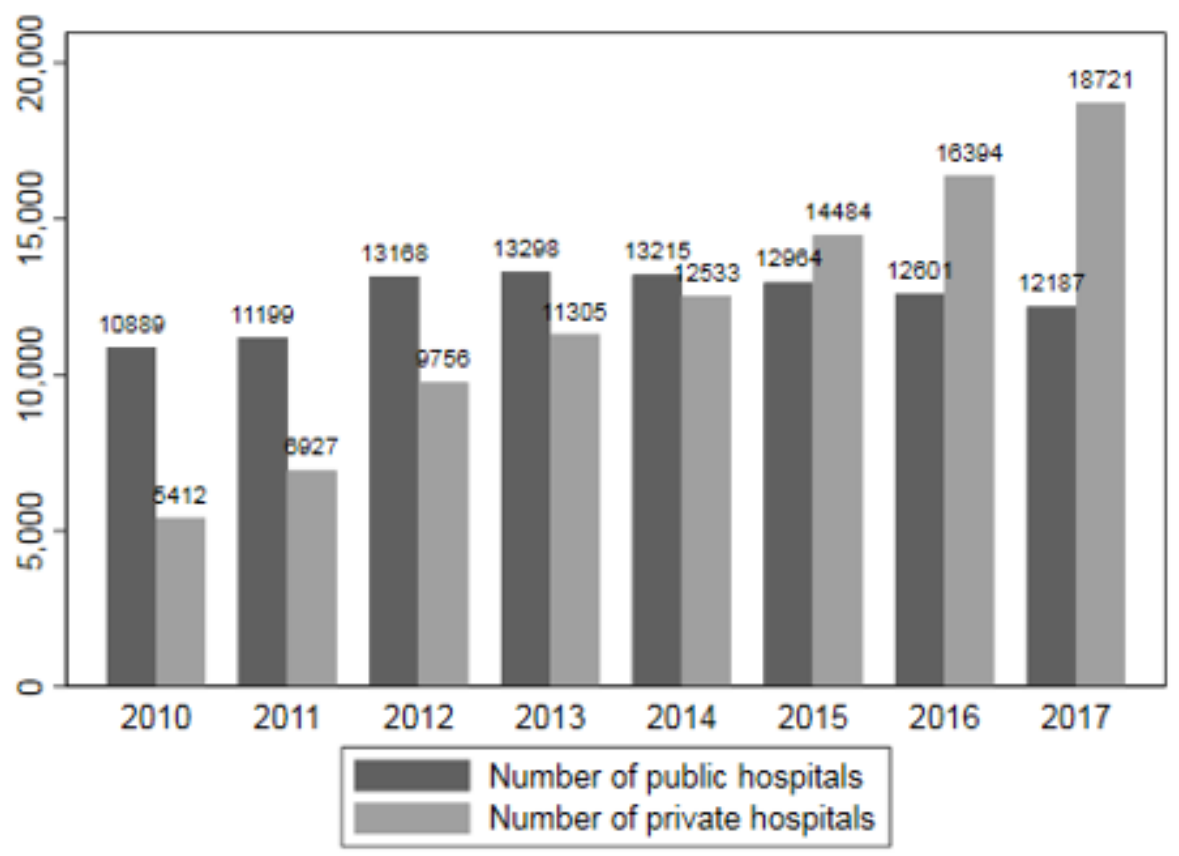

Figure 1

Comparison of number of private hospitals and not-private hospitals. Data source: China Health Statistics Yearbook, published by National Health and Health Commission 